\title{
Basal serum cortisol and adrenocorticotropic hormone levels in patients with atopic dermatitis
}

\author{
Zohreh Tehranchinia ${ }^{1}$, Hoda Rahimi ${ }^{1}$, Sara Lotfi ${ }^{1}$
}

1 Department of Dermatology, Skin Research Center, Shahid Behehshti University of Medical Sciences, Tehran, Iran

Key words: adrenocorticotropic hormone, atopic dermatitis, cortisol, IgE

Citation: Tehranchinia Z, Rahimi H, Lotfi S. Basal serum cortisol and adrenocorticotropic hormone levels in patients with atopic dermatitis. Dermatol Pract Concept 2017;7(4):25-29. DOI: https://doi.org/10.5826/dpc.0704a07

Received: December 11, 2016; Accepted: June 21, 2017; Published: October 31, 2017

Copyright: $\odot 2017$ Tehranchinia et al. This is an open-access article distributed under the terms of the Creative Commons Attribution License, which permits unrestricted use, distribution, and reproduction in any medium, provided the original author and source are credited.

Funding: None.

Competing interests: The authors have no conflicts of interest to disclose.

All authors have contributed significantly to this publication.

Corresponding author: Zohreh Tehranchinia, MD, Associate Professor of Dermatology, Skin Research Center, Shohada-e Tajrish Hospital, Shabid Behehshti University of Medical Sciences, Tehran, Iran, 1989934148. Email: zohreh_tehranchi@yahoo.com

ABSTRACT Background: Certain studies suggest that percutaneous absorption of topical steroids may cause suppression of hypothalamic-pituitary-adrenal axis (HPAA) in atopic dermatitis (AD) patients. This study aimed to investigate the basal serum cortisol, adrenocorticotropic hormone (ACTH), and IgE levels in patients with $\mathrm{AD}$ and their correlation with the disease severity.

Methods: Levels of basal serum cortisol, ACTH, and IgE were assessed by ELISA in 31 patients with $\mathrm{AD}$ and 31 controls. Clinical severity of $\mathrm{AD}$ was evaluated by the scoring of atopic dermatitis (SCORAD) index.

Results: No statistical difference was observed between the two groups for basal serum cortisol and ACTH levels. The serum IgE level was significantly higher in the AD group. The SCORAD index was correlated with serum IgE level.

Conclusions: Basal serum cortisol and ACTH levels are normal in AD patients. Serum IgE level is significantly higher in $\mathrm{AD}$ patients and is correlated with the disease severity.

\section{Introduction}

Atopic dermatitis $(\mathrm{AD})$ is an inflammatory skin disease with an onset in infancy or early childhood and is characterized by severe pruritus, chronic and relapsing course, and typical clinical morphology including xerosis and eczematous lesions $[1,2]$. The incidence of $\mathrm{AD}$ has increased in the past 30 years, whereas its current prevalence is estimated to be $12 \%$. Atopic dermatitis is often associated with remarkable morbidity, which results in patient hospitalization, absence from work or school, and loss of several working days [3,4]. In children, sleep disorders leading to behavioral disturbances are known to be one of the most hazardous effects of AD [5,6]. Furthermore, this disease may cause growth retardation in children [7]. Unpredictable course, chronic and relapsing nature of the disease, and disturbing pruritus can impose extensive psychological and emotional burden on patients with $\mathrm{AD}$ and their families [8-11]. 
TABLE 1. Demographics and clinical data of patients and controls

\begin{tabular}{|c|c|c|c|}
\hline & Patients (N=31) & Controls $(\mathrm{N}=31)$ & P Value \\
\hline \multicolumn{4}{|l|}{ Age, years } \\
\hline Mean \pm SD & $34.1 \pm 19.2$ & $35.6 \pm 17.3$ & 0.75 \\
\hline Range & $0.5-78$ & $1-80$ & \\
\hline Median & 28 & 30 & \\
\hline \multicolumn{4}{|l|}{ Gender } \\
\hline Female & 22 & 23 & 0.86 \\
\hline Male & 9 & 8 & \\
\hline \multicolumn{4}{|c|}{ Disease Duration, Years } \\
\hline Mean & 7.1 & - & \\
\hline Range & $0.5-21$ & - & \\
\hline
\end{tabular}

Topical corticosteroids are the most widely used and the mainstay of treatment for AD [12], but there is increasing concern about their systemic side effects, especially adrenal suppression. There is some evidence that the percutaneous systemic absorption of topical steroids may occur after the prolonged use of these drugs and may lead to the suppression of hypothalamic-pituitary-adrenal axis (HPAA) [13,14]; however, in the majority of these studies, "basic" HPAA function (before application of topical steroids) remained unevaluated. In other words, in most of these studies, the HPAA function was compared with controls only "after" the application of topical steroids. Few studies have evaluated the basic HPAA function, especially in children; however, the results are conflicting [15-17].

This study aimed to evaluate the basal serum cortisol, adrenocorticotropic hormone (ACTH), and IgE levels in patients with $\mathrm{AD}$ (without any age limitation) and their correlation with the disease severity.

\section{Patients and Methods}

\section{Patients}

This study included 31 patients (22 females and 9 males) with mean age of $34.1 \pm 19.2$ years (range $0.5-78$ years) who were visited by dermatologists and were diagnosed as $\mathrm{AD}$, according to the criteria of Hanifin and Rajka [1], and 31 age- and sex-matched control subjects. The control subjects had neither self-reported allergies or allergic symptoms, nor any inflammatory skin disease. Subjects with history of treatment with any systemic steroids during the previous year or topical steroids during the previous month, history of adrenal insufficiency, Cushing's syndrome, active inflammation, alcoholism, and depression were excluded from the study. The study was carried out in accordance with the ethical standards established in the Declaration of Helsinki, and informed consent was obtained from all participants or their parents (if age $<16$ years), before participation.

\section{Investigations}

Morning basal serum cortisol levels at $8 \mathrm{AM}$ (expected value: male $5-22 \mathrm{mg} / \mathrm{dL}$; female $5.2-21.7 \mathrm{mg} / \mathrm{dL}$; sensitivity 0.25 $\mathrm{mg} / \mathrm{dL}$, serum ACTH levels (expected value: $17-58.2 \mathrm{pg} /$ $\mathrm{mL}$; sensitivity $0.22 \mathrm{pg} / \mathrm{mL}$ ), and serum IgE levels (positive expected value>190 IU/ml; sensitivity $25 \mathrm{IU} / \mathrm{ml}$ ) were measured using the enzyme link immunosorbent assay (ELISA; Biomerica, CA, USAin the case and control groups.

\section{Disease Severity}

Clinical severity of the disease was evaluated by the scoring of atopic dermatitis (SCORAD) index and was graded as mild (SCORAD $<25$ ), moderate (SCORAD: 25-50), and severe $(\mathrm{SCORAD}>50)$ [18].

\section{Statistical Analysis}

All statistical analyses were performed using SPSS 16.0 (SPSS Inc, Chicago, IL, USA). To assess the quantitative variables, student's t-test and Mann-Whitney U test were used for independent groups and categorical variable, as appropriated. Spearman correlation test was used to assess the correlation between variables. $\mathrm{P}<0.05$ was considered as statistically significant.

\section{Results}

This study included 31 patients with vitiligo and 31 healthy controls. Demographics and clinical data of patients and controls are summarized in Table 1. Basal serum cortisol level was found to be higher than the reference range in one patient from the $\mathrm{AD}$ group $(3.2 \%)$; however, none of the 


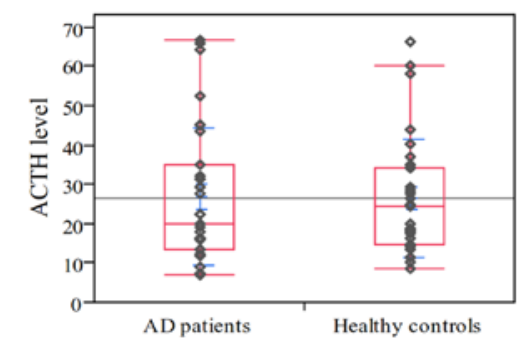

(A)

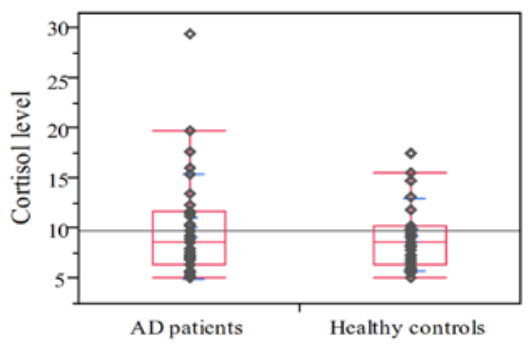

(B)

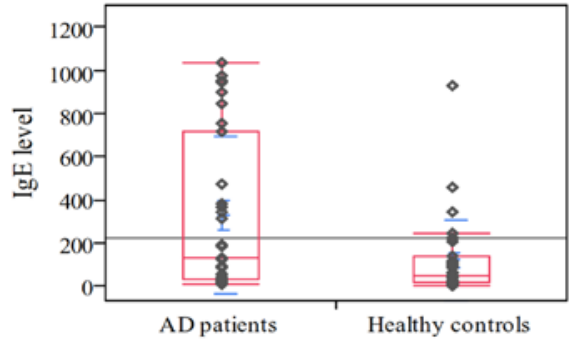

(C)

Figure 1. Comparison of serum levels of $(\mathrm{A}) \mathrm{ACTH}(\mathrm{p}>0.05)$, (B) cortisol $(\mathrm{p}>0.05)$, and $(\mathrm{C})$ total igE $(\mathrm{p}<0.05)$ in patients with atopic dermatitis and healthy controls. Data shown as median (horizontal line), 25th to 75th percentiles (box), and range (capped lines). [Copyright: (C2017 Tehranchinia et al.]

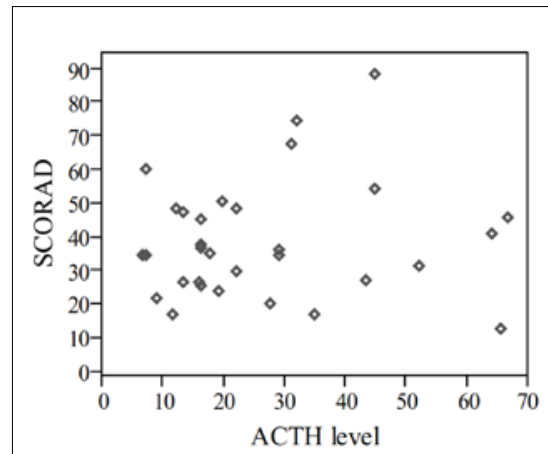

(A)

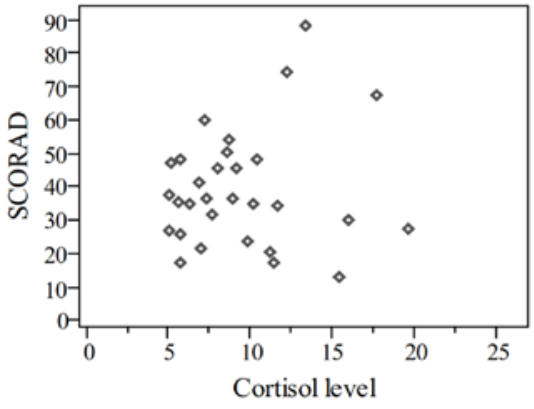

(B)

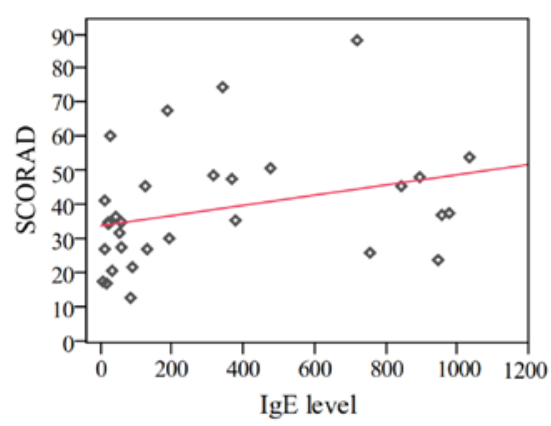

(C)

Figure 2. Correlation between SCORAD index and serum levels of ACTH, cortisol, and total IgE. There was no correlation between serum ACTH (A) or basal cortisol levels (B) and SCORAD index. Total serum igE level was positively correlated with SCORAD index. [Copyright: C2017 Tehranchinia et al.]

TABLE 2. Disease severity evaluated by SCORAD index in patients with atopic dermatitis

\begin{tabular}{|l|c|}
\multicolumn{1}{|c|}{ Disease Severity } & N (\%) \\
\hline Mild (SCORAD<25) & $6(19.86)$ \\
\hline $\begin{array}{l}\text { Moderate }(\text { SCORAD: } \\
\text { 25-50) }\end{array}$ & $19(61.28)$ \\
\hline Severe $($ SCORAD $>50)$ & $6(19.36)$ \\
\hline
\end{tabular}

subjects from the control group displayed high basal serum cortisol level. This difference was not significant $(P=0.63)$. The mean of basal serum cortisol level was $10.09 \pm 5.24 \mathrm{mg} /$ $\mathrm{dL}$ (range 5.1-29.4) in the $\mathrm{AD}$ group and $9.32 \pm 3.59 \mathrm{mg} / \mathrm{dL}$ (range 5-17.5) in the control group. The mean of basal serum cortisol level between the two groups showed no statistical significant difference $(P=0.67)$.

The mean of ACTH level in the AD group was $26.76 \pm 17.57$ $\mathrm{pg} / \mathrm{mL}$ (range 6.8-66.8), whereas it was $26.42 \pm 14.92$ in the control subjects. The mean of ACTH level between two groups showed no statistical significant difference $(P=0.74)$

The mean of serum IgE level was $328.48 \pm 362.77 \mathrm{IU} / \mathrm{mL}$ (range 8-1033) in the AD group and $121.55 \pm 185.47$ (range
5-932) in the control group. As expected, the serum IgE level was significantly higher in the $\operatorname{AD}$ group $(P=0.02$; Figure 1$)$.

Most of our patients displayed moderate $\mathrm{AD}$ according to the SCORAD index. Table 2 summarizes SCORAD grading in our patients. The SCORAD index was correlated with serum IgE level $(P<0.05$; rs=0.41), but not with the basal serum cortisol level $(P=0.87$; rs=0.03) and ACTH level $(P=0.53$; $\mathrm{rs}=0.12$; Figure 2). SCORAD index was not correlated with age, sex, and clinical features of AD.

\section{Discussion}

In this case-control study, no significant difference was observed in the basal serum cortisol and ACTH levels in patients with $\mathrm{AD}$ and the control group. Interestingly, we found that the severity of AD (SCORAD index) correlated with serum IgE level, but not with the serum cortisol level. The literature review reveals various studies with distinct research designs and methodologies and conflicting results (Table 3).

A study by Matsuda et al., reported significantly lower basal cortisol levels and lower response to ACTH in AD 
TABLE 3. Different studies evaluating serum cortisol levels in patients with atopic dermatitis

\begin{tabular}{|c|c|c|c|}
\hline Authors & Study population & Result & Comments \\
\hline Matsuda et al. [17] & Children with AD & $\downarrow$ Response to ACTH & $\begin{array}{l}\text { Control group was selected } \\
\text { from asthmatic children }\end{array}$ \\
\hline Patel et al. [19] & $\begin{array}{l}\text { Children with moderate to } \\
\text { severe AD who were under } \\
\text { regular treatment with } \\
\text { corticosteroid }\end{array}$ & Normal basal cortisol levels & \\
\hline Haeck et al. [16] & $\begin{array}{l}\text { Patients with moderate or } \\
\text { severe AD }\end{array}$ & $\begin{array}{l}\text { AD activity is responsible for } \\
\text { low basal cortisol levels }\end{array}$ & $\begin{array}{l}\text { Two years later, the authors } \\
\text { confessed that their results } \\
\text { were incorrect [20] }\end{array}$ \\
\hline Natan et al. [21] & Children with AD & $\begin{array}{l}\downarrow \text { Basal cortisol level in } 50 \% \\
\text { of patients, which was in } \\
\text { correlation with disease } \\
\text { severity } \\
\downarrow \text { ACTH response. } \\
\text { Recovery of the HPAA after } \\
\text { application of topical steroid }\end{array}$ & \\
\hline Afsar et al. [22] & Children with $\mathrm{AD}$ & $\begin{array}{l}\text { Normal basal cortisol level } \\
\text { with no correlation with } \\
\text { disease severity }\end{array}$ & \\
\hline
\end{tabular}

AD: atopic dermatitis; ACTH: adrenocorticotropic hormone; HPAA: hypothalamic-pituitary-adrenal axis.

children than the control group, providing an evidence of impaired HPAA function in patients with AD [17]; however, the main pitfall of this study was that their control group consisted of asthmatic patients. As asthma itself lies in the spectrum of atopia and forms one of the three parts of allergic triad ( $\mathrm{AD}$, allergic rhinitis, and asthma), selecting controls from asthmatic patients may result in an inappropriate and biased comparison.

A study which has been the mainstay and reference of most of recent investigations is the report of Haeck et al., which demonstrated lower basal cortisol level in patients with severe, active AD (group 1) than the patients with moderate, controlled AD (group 2). Furthermore, this study found no significant correlation between the amount of prescribed topical corticosteroid and serum cortisol levels, and concluded that disease activity, rather than the use of topical corticosteroids, is responsible for the low basal cortisol values in patients with severe AD [16]. Nevertheless, two years later, the authors of this article confessed that they had made a fatal flaw in the execution of their study, which led to wrong interpretation and incorrect conclusion [20]. Surprisingly, none of the recent studies has referred to this corrigendum.

Afsar et al. reported that none of the pediatric patients with AD had basal serum cortisol levels below the lower limit of the reference range, and no difference was observed in the basal cortisol values when they were compared with those of the control group. They also reported that the severity of AD did not correlate with the serum cortisol values in the pediatric AD group [22]. The results of this study were compatible with our findings, although it was performed only on pediatric patients.

We found a positive correlation between the total serum $\mathrm{IgE}$ values and disease severity, and our study is in correlation with the results of Choen et al. [23].

In conclusion, in the present study no difference was observed in both basal cortisol levels and ACTH values between the AD and control groups. The basal cortisol levels were not correlated with the disease severity, whereas the serum IgE level was significantly higher in AD patients and correlated with the disease severity. To the best of our knowledge, this was the first case-control study that evaluated HPAA in AD patients without any age limitation. The limitation of our study was its sample size; thus, further studies with larger sample size are necessary to investigate the complex interaction of the neuroendocrine, metabolic, and immune systems and to explain the available conflicting results.

\section{References}

1. Hanifin JM, Rajka G. Diagnostic features of atopic dermatitis. Acta Derm Venreol. 1980;92:44-47.

2. Williams HC. Epidemiology of human atopic dermatitis-seven areas of notable progress and seven areas of notable ignorance. Vet Dermatol. 2013;24:3-9.e1-2.

3. Madhok V, Futamura M, Thomas KS, Barbarot S. What's new in atopic eczema? An analysis of systematic reviews published in 
2012 and 2013. Part 1. Epidemiology, mechanisms of disease and methodological issues. Clin Exp Dermatol. 2015;40:238-242.

4. Van Moerbeke D. European Allergy White Paper. Allergic Disease as a Public Health Problem in Europe. Brussels: UCB Institute of Allergy. 1997.

5. Yaghmaie P, Koudelka CW, Simpson EL. Mental health comorbidity in patients with atopic dermatitis. J Allergy Clin Immunol. $2013 ; 131: 428-33$.

6. Kong TS, Han TY, Lee JH, Son SJ. Correlation between severity of atopic dermatitis and sleep quality in children and adults. Ann Dermatol. 2016;28:321-326.

7. Palit A, Handa S, Bhalla AK, Kumar B. A mixed longitudinal study of physical growth in children with atopic dermatitis. Indian J Dermatol Venereol Leprol. 2007;73:171-175.

8. Whiteley J, Emir B, Seitzman R, Makinson G. The burden of atopic dermatitis in US adults: results from the 2013 National Health and Wellness Survey. Curr Med Res Opin. 2016; 21:1-7.

9. Al Shobaili HA. The impact of childhood atopic dermatitis on the patient's family. Pediatr Dermatol. 2010;27:618-623.

10. McKenna SP, Doward LC. Quality of life of children with atopic dermatitis and their families. Curr Opin Allergy Clin Immunol. 2008;8:228-231.

11. Lewis-Jones S. Quality of life and childhood atopic dermatitis: the misery of living with childhood eczema. Int J Clin Pract. 2006;60:984-992.

12. Eichenfield LF, Tom WL, Berger TG, et al. Guidelines of care for the management of atopic dermatitis: section 2. Management and treatment of atopic dermatitis with topical therapies. J Am Acad Dermatol. 2014;71:116-132.

13. Silverberg JI, Nelson DB, Yosipovitch G. Addressing treatment challenges in atopic dermatitis with novel topical therapies. J Dermatol Treat. 2016;11:1-9.

14. Siegfried EC, Jaworski JC, Kaiser JD, Hebert AA. Systematic review of published trials: long-term safety of topical corticosteroids and topical calcineurin inhibitors in pediatric patients with atopic dermatitis. BMC Pediatr. 2016 16:75.

15. Buske-Kirschbaum A, von Auer K, Krieger S, Weis S, Rauh W, Hellhammer D. Blunted cortisol responses to psychosocial stress in asthmatic children: a general feature of atopic disease? Psychosom Med. 2003;65:806-810.

16. Haeck IM,Timmer-de Mik L, Lentjes EGWM, et al. Low basal serum cortisol in patients with severe atopic dermatitis: potent topical corticosteroids wrongfully accused. $\mathrm{Br} J$ Dermatol. 2007;156:979-985.

17. Matsuda K, Katsunuma T, Iikura Y, Kato H, Saito H, Akasawa A. Adrenocortical function in patients with severe atopic dermatitis. Ann Allergy Asthma Immunol. 2000;85:35-39.

18. Gelmetti C, Colonna C. The value of SCORAD and beyond. Towards a standardized evaluation of severity? Allergy. 2004;59:6165.

19. Patel L, Clayton PE, Addison GM, Price DA, David TJ. Adernal function following topical steroid treatment in children with atopic dermatitis. Br J Dermatol. 1995;132:950-955.

20. Haeck IM,Timmer-de Mik L, Lentjes EGWM, et al. Erratum to Low basal serum cortisol in patients with severe atopic dermatitis: potent topical corticosteroids wrongfully accused. Br J Dermatol. 2009;161:218.

21. Nutan, Kanwar AJ, Bhansali A, Parsad D. Evaluation of hypothalamic-pituitary-adrenal axis in patients with atopic dermatitis. Indian J Dermatol Venereol Leprol. 2011;77:288-293.

22. Afsar FS, Isleten F, Sonmez N. Children with atopic dermatitis do not have more anxiety or different cortisol levels compared with normal children. J Cutan Med Surg. 2010;14:13-18.

23. Cheon BR, Shin JE, Kim YJ, et al. Relationship between serum 25-hydroxyvitamin D and interleukin-31 levels, and the severity of atopic dermatitis in children. Korean J Pediatr. 2015;58:96-101. 